\title{
Excess mortality in England and Wales, and in Greater London, during the 1995 heatwave
}

\author{
Cleone Rooney, Anthony J McMichael, R Sari Kovats, Michel P Coleman
}

\begin{abstract}
Study objective-To assess the impact on mortality of the heatwave in England and Wales during July and August 1995 and to describe any difference in mortality impact between the Greater London urban population and the national population. Design-Analysis of variation in daily mortality in England and Wales and in Greater London during a five day heatwave in July and August 1995, by age, sex, and cause.

Setting-England and Wales, and Greater London.

Main results-An estimated 619 extra deaths $(8.9 \%$ increase, approximate $95 \%$ confidence interval $6.4,11.3 \%$ ) were observed during this heatwave in England and Wales, relative to the expected number of deaths based on the 31-day moving average for that period. Excess deaths were apparent in all age groups, most noticeably in women and for deaths from respiratory and cerebrovascular disease. Using published daily mortality risk coefficients for air pollutants in London, it was estimated that up to $62 \%$ of the excess mortality in England and Wales during the heatwave may be attributable to concurrent increases in air pollution. In Greater London itself, where daytime temperatures were higher (and with lesser falls at night), mortality increased by $16.1 \%$ during the heatwave. Using the same risk coefficients to estimate the excess mortality apparently attributable to air pollution, more than $60 \%$ of the total excess in London was apparently attributable to the effects of heat.

Conclusion-Analysis of this episode shows that exceptionally high temperatures in England and Wales, though rare, do cause increases in daily mortality.

(F Epidemiol Community Health 1998;52:482-486)
\end{abstract}

Drummond Gate,

London SW1V 2QQ

C Rooney

M P Coleman

Department of

Epidemiology and

Population Health,

London School of

Hygiene and Tropical

Medicine, London

A J McMichael

R S Kovats

M P Coleman

Correspondence to:

Dr Rooney.

Accepted for publication 18 February 1998 predominantly conducted in the US, have shown that those most vulnerable to heatrelated mortality are the aged and the urban poor. ${ }^{23}$ Recently, a case-control study ${ }^{4}$ of deaths during the 1995 heatwave in Chicago identified several categories of vulnerable person. These included people who were bedridden and those living in homes that were poorly ventilated or not air conditioned.

With its relatively stable maritime climate, temperature extremes are rarer in England and Wales than in countries with continental climates such as the USA. Although increases in summertime daily mortality during "hot spells" have previously been documented, ${ }^{56}$ there have been few quantitative assessments of heat-related mortality in the UK or of determinants of vulnerability to heatwaves here.

Death rates in England and Wales oscillate seasonally, being lower in summer than in winter months. ${ }^{7}$ In temperate countries, the daily number of deaths at any time of the year is generally lowest within an intermediate range of daily outdoor temperatures, and there is often a threshold temperature above which daily mortality increases steeply. ${ }^{89}$ The local threshold temperature varies between populations, probably through physiological acclimatisation and cultural adaptation in clothing and housing, ${ }^{2}$ and the upturn in daily mortality is more evident in some populations (for example, Shanghai) than in others (for example, Guangzhou). ${ }^{9}$ Recent analyses of urban populations in the USA, Canada, the Netherlands, China, and the Middle East indicate that allcause mortality rises during heatwaves. ${ }^{389}$

Extremes of temperature and air pollution both cause increases in daily mortality, although few studies have estimated their independent effects. ${ }^{3}$ Increases in levels of ozone, fine particulates, and nitrogen dioxide are associated with increases in all-cause daily mortality; ozone particularly affects respiratory and cardiovascular daily mortality. ${ }^{10}$ To elucidate the extent and nature of the mortality impact of heatwaves in England and Wales, we have analysed data from the exceptionally hot spell from 30 July to 3 August during the very hot summer of 1995 . We compared daily deaths during this five-day episode with the expected numbers of deaths estimated from recorded daily deaths during 1993-95 in England and Wales. We also assessed the extent to which air pollution may have accounted for any observed excess mortality during the episode. We repeated this analysis for the population of Greater London separately, to assess the effects of heat and air pollution in a large city. 


\section{Methods}

From the national mortality database held by the Office for National Statistics, we extracted the daily numbers of deaths by date of death (that is, not the date when the death was registered) for 1993-95. For 1995, we also extracted the daily number of deaths by sex, broad age group (0-15 years, 16-64, 65-74, $75-84,85$ and over) and for selected broad categories of cause of death: neoplasms (ICD-9 codes 140-239), ischaemic heart disease (410414), cerebrovascular disease (430-438), and respiratory disease (460-519).

Central England Temperature (CET) is a weighted mean temperature for England and Wales derived from measurements at four dispersed meteorological stations (Squires Gate, Lancs; Manchester Airport; Malvern, Worcs; and Rothamsted, Herts) and corrected for small effects of urban warming. ${ }^{11}$ We obtained from the UK Meteorological Office the daily CET for 1993-95 and daily temperatures for London for 1995.

The daily number of deaths from all causes and the daily mean CET were plotted for the months of May to September 1995. Similar analyses were carried out for selected causes of death and for each sex and age group. The 31day moving average values (including the 15 days on either side of the index day) for daily mortality were calculated both for 1993 and 1994 combined and for 1995 . Excess mortality in the heatwave was assessed as the difference between the number of deaths observed on a given day and the corresponding moving average value, separately for 1993-94 and for 1995 . The preferred estimate for the excess mortality is that based on comparison with 1995, although this is marginally more conservative, as the values for heatwave days are included in the average values. An approximate confidence interval for the excess mortality was obtained by treating the total number of deaths during the heatwave as a Poisson variable, and comparing the upper and lower 95\% confidence bounds of this value with the expected number of deaths. A slightly less conservative estimate of the excess mortality during the heatwave can be obtained by assuming that, in the absence of the heatwave, the number of deaths on heatwave days could be estimated by linear interpolation between the number of deaths on the immediately preceding (29 July) and succeeding (4 August) days, and recalculating the 31-day moving average values for 1995 accordingly.

We obtained daily atmospheric concentrations of ozone, respirable fine particulates $\left(\mathrm{PM}_{10}\right.$, particulate matter with diameter $\leqslant 10$ microns) and nitrogen dioxide measured at selected sites in England in 1995 from AEA Technology (formerly part of the United Kingdom Atomic Energy Authority) at the National Environmental Technology Centre. The monitoring sites included several in inner and outer London and both rural and urban sites outside London. To estimate the approximate impact of these air pollutants on daily mortality during the 1995 heatwave, we used the published season-specific risk coefficients derived recently for London ${ }^{10}$ (there being no comparable set of coefficients for either England and Wales as a whole or for areas outside London). These linear coefficients estimate

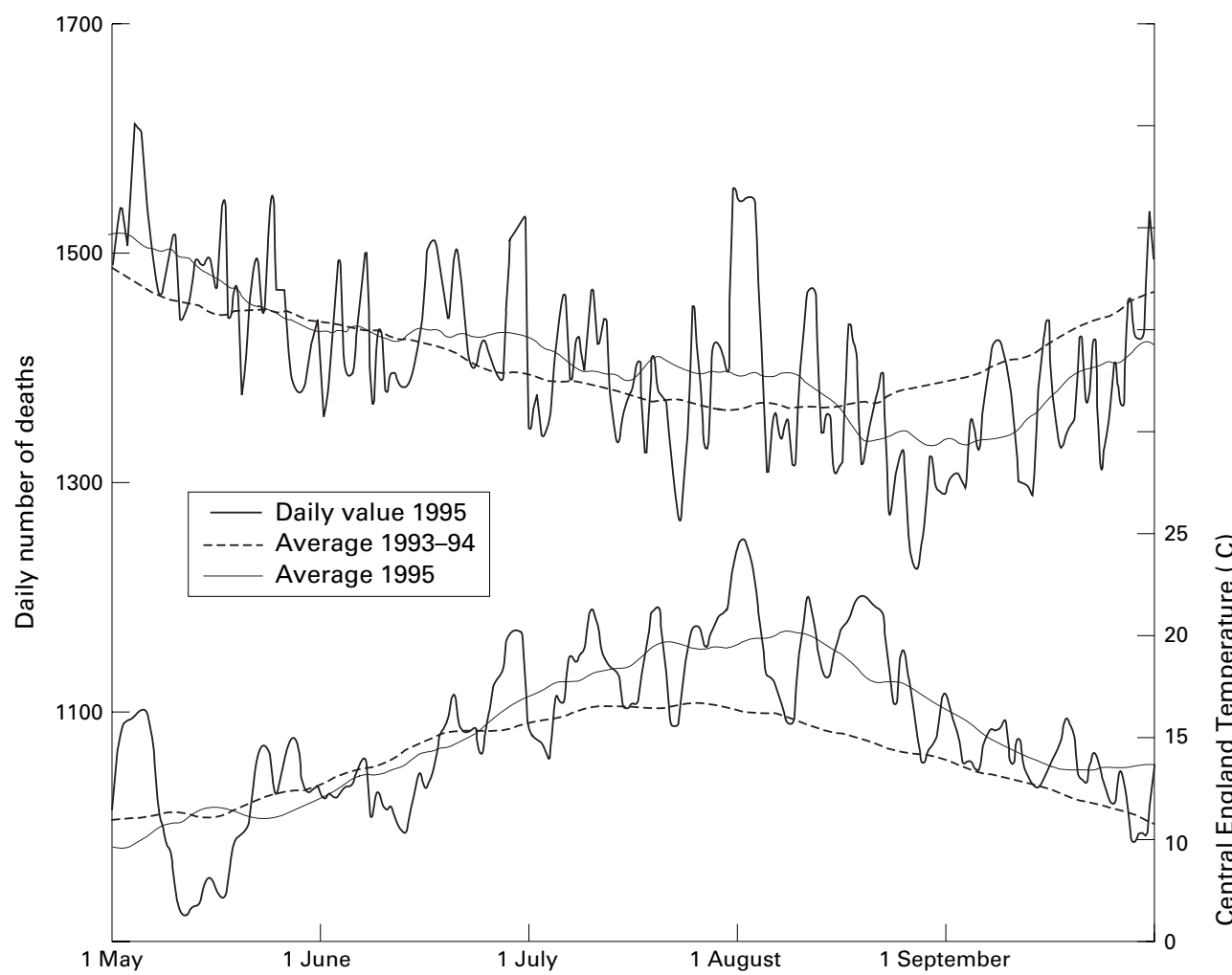

Figure 1 Daily number of deaths in England and Wales and mean daily Central England Temperature $\left({ }^{\circ} \mathrm{C}\right)$, May to September 1995; with 31-day moving averages for 1993-94 and 1995. 
Table 1 Total and excess deaths in England and Wales during the five-day heatwave in 1995, by age, sex, and cause

\begin{tabular}{|c|c|c|c|c|c|c|}
\hline & \multicolumn{3}{|c|}{ England and Wales } & \multicolumn{3}{|c|}{ Greater London } \\
\hline & \multirow{2}{*}{$\begin{array}{l}\text { Observed } \\
\text { deaths } \\
\text { Number }\end{array}$} & \multicolumn{2}{|c|}{ Excess deaths } & \multirow{2}{*}{$\begin{array}{l}\text { Observed } \\
\text { deaths } \\
\text { Number }\end{array}$} & \multicolumn{2}{|c|}{ Excess deaths } \\
\hline & & Number & $\%$ & & Number & $\%$ \\
\hline & Compared & ith 1993- & & Compared & vith 1993 & \\
\hline \multirow[t]{2}{*}{ All ages } & 7600 & 768.2 & 11.2 & 986 & 184.1 & 23.0 \\
\hline & \multicolumn{3}{|c|}{ Compared with 1995} & \multicolumn{3}{|c|}{ Compared with 1995} \\
\hline \multicolumn{7}{|l|}{$\operatorname{Age}(y)$} \\
\hline $0-15$ & 77 & 3.4 & 4.6 & 13 & 1.5 & 13.0 \\
\hline $16-64$ & 1253 & 95.1 & 8.2 & 196 & 26.4 & 15.6 \\
\hline $65-74$ & 1719 & 133.7 & 8.4 & 201 & 23.5 & 13.2 \\
\hline $75-84$ & 2486 & 195.2 & 8.5 & 300 & 38.9 & 14.9 \\
\hline 85 and over & 2065 & 192.2 & 10.3 & 276 & 46.2 & 20.1 \\
\hline All ages & 7600 & 619.5 & 8.9 & 986 & 136.5 & 16.1 \\
\hline \multicolumn{7}{|l|}{ Sex } \\
\hline Male & 3515 & 205.2 & 6.2 & 442 & 33.8 & 8.3 \\
\hline Female & 4085 & 414.4 & 11.3 & 544 & 102.7 & 23.3 \\
\hline \multicolumn{7}{|l|}{ Cause of death } \\
\hline Neoplasms & 2018 & 100.7 & 5.3 & 259 & 27.8 & 12.0 \\
\hline Ischaemic heart disease & 1675 & 125.4 & 8.1 & 184 & 9.8 & 5.6 \\
\hline Cerebrovascular disease & 834 & 84.7 & 11.3 & 101 & 28.3 & 38.9 \\
\hline Respiratory disease & 1102 & 121.8 & 12.4 & 157 & 21.3 & 15.7 \\
\hline
\end{tabular}

the percentage increase in deaths for a given absolute increase in the level of pollutant. The daily levels of nitrogen dioxide and respirable fine particulates observed during the 1995 heatwave were within the ranges used to derive these coefficients, although the average ozone level during the heatwave was about twice the 90th percentile of this range.

To estimate additional daily deaths attributable to pollution, the excess of daily pollutant levels during the heatwave over the average level for the two month period July-August 1995 was multiplied by the corresponding warm season coefficient. We assumed the effects of individual air pollutants to be independent and therefore additive, there being no clear evidence to the contrary from published research. Air pollution levels in the UK are relatively high in London, and ozone levels are higher and more frequently raised in the southern parts of the UK. ${ }^{12}$ London mortality coefficients were therefore used to provide an upper estimate of the probable impact of increased air pollution on the heatwave-associated daily mortality in England and Wales.

\section{Results}

The unusually hot summer in 1995 is evident from the 31-day moving average of temperature (fig 1). Relative to 1993-94, mean daily temperatures were on average $3^{\circ} \mathrm{C}$ higher during the period June to September.

There was a short, sharp peak in the daily number of deaths in late July and early August

\section{KEY POINTS}

- Daily deaths in England and Wales during the 1995 heatwave rose $8.9 \%$ above the seasonal average.

- The effect was greater for respiratory disease $(12.4 \%)$ and cerebrovascular disease $(11.3 \%)$.

- The overall increase in mortality was much larger (16.1\%) in Greater London.

- Concurrent air pollution may account for about $38 \%$ of the excess mortality in Greater London, but up to $62 \%$ in England and Wales.

- The higher excess mortality in Greater London may be because of higher nighttime temperatures and greater deprivation.

1995, at around the time when the daily number of deaths is usually at an annual minimum. This mortality peak coincided with the five day heatwave, from 30 July to 3 August, that peaked with a mean CET of $24.9^{\circ} \mathrm{C}$ on 1 August, the hottest day of the year (fig 1).

The estimated mid-year population of England and Wales in 1995 was 51820200 and the total number of deaths that occurred in that year was 578799 . An estimated 768 extra deaths occurred during the five heatwave days relative to the average mortality for the corresponding periods in 1993 and 1994, an $11.2 \%$ increase (table 1 ). Several smaller peaks in daily mortality occurred in May, June, and July, coinciding with lesser peaks in temperature before the heatwave. The excess mortality during the 1995 heatwave was apparent in all age groups, but was more noticeable in women (table 1). The preferred (more conservative) estimate of excess mortality, with baseline mortality derived from the moving average values for 1995, indicated an excess of 619 deaths $(8.9 \%)^{\star}$ with an approximate $95 \%$ confidence interval of 449,790 deaths $(6.4,11.3 \%)$. The effect was most pronounced for respiratory disease (12.4\% increase), and for cerebrovascular disease ( $11.3 \%$ increase).

In Greater London, an estimated 184 extra deaths occurred during these five days relative to the average mortality for 1993-94,

*The alternative 1995 based estimate (see Methods), in which deaths on heatwave days were interpolated from the daily number of deaths before and after the heatwave when calculating the 31-day moving averages, gave an overall excess mortality of $10.2 \%$ (calculations not shown).

Table 2 Average air pollutant concentrations from selected Department of the Environment monitoring sites during fuly and August 1995

\begin{tabular}{|c|c|c|c|c|c|}
\hline Pollutant & Locality & 5 day mean & & & $\begin{array}{l}\text { fuly/August } \\
\text { mean }\end{array}$ \\
\hline \multirow{3}{*}{ Ozone ${ }^{\star}$ (parts per billion) } & & 24-28 July & 29 July-2 August & 3-7 August & \\
\hline & London & $39.8+$ & 56.8 & 35.6 & 34.95 \\
\hline & Urban (+ 1 rural site $) \ddagger$ outside London & $\begin{array}{l}46.5 \\
25-29 \text { July }\end{array}$ & $\begin{array}{l}65.4 \\
30 \text { July-3 August }\end{array}$ & $\begin{array}{l}41.5 \\
4-8 \text { August }\end{array}$ & 43.01 \\
\hline \multirow[t]{2}{*}{ Nitrogen dioxide $₫$ (parts per billion) } & London & 41.0 & 54.3 & 31.2 & 36.84 \\
\hline & Urban outside London & 22.1 & 28.7 & 20.6 & 20.44 \\
\hline \multirow[t]{2}{*}{ Particulates $\left(\leqslant 10\right.$ microns diameter) $\left(\mu \mathrm{g} / \mathrm{m}^{3}\right) \uparrow$} & London & 41.0 & 56.8 & 28.0 & 38.80 \\
\hline & Urban outside London & 27.6 & 46.5 & 25.8 & 29.86 \\
\hline
\end{tabular}

${ }^{\star}$ Highest daily value of 8 hour running averages. $†$ Mortality estimated with one day lag. $\ddagger$ Ozone may reach significant concentrations in rural areas, depending on local weather conditions. §Daily average. $\mid$ Highest daily value of 24 hour running averages. 
representing an excess of $23.0 \%$. The preferred estimate of excess mortality (relative to 1995) was $16.1 \%$, after direct age adjustment of the age specific excess mortality to the age distribution of England and Wales. The excess mortality in Greater London was also more pronounced in women, and for cerebrovascular disease (38.9\% increase). During the heatwave, maximum temperatures in London were similar to the CET value but minimum temperatures were higher. For example, on 1 August, the maximum and minimum daily temperatures were $31.9^{\circ} \mathrm{C}$ and $17.9^{\circ} \mathrm{C}$ for Central England and $32.1^{\circ} \mathrm{C}$ and $20.9^{\circ} \mathrm{C}$ at the London Weather Centre.

Air pollutant levels at all sites also rose during the heatwave (table 2). Levels of ozone were increased particularly in rural and suburban areas, which accords with what is known about the gradual process of ozone formation from its precursor pollutants in drifting air. During July and August 1995, concentrations of nitrogen oxide and $\mathrm{PM}_{10}$ were consistently higher in London than in other cities. This pattern of air pollution is consistent with other studies in the UK. ${ }^{12}$ By adding the estimates of extra deaths attributable to each of the three main air pollutants, we estimated that the above average exposures could have accounted, at most, for an approximate 5.5\% increase in daily mortality in England and Wales (compared with 1995 levels) during the heatwave. A similar estimate applied to Greater London. The estimated excess mortality attributable to specific air pollutants outside London was: particulates $2.4 \%$; ozone $2.7 \%$; and nitrogen dioxide $0.4 \%$. In Greater London the estimated contributions were: particulates $2.6 \%$; ozone $2.6 \%$; and nitrogen dioxide $0.9 \%$.

\section{Discussion}

We have examined mortality in England and Wales during the 1995 heatwave, using average measures of temperature and air pollution. The five-day heatwave was associated with an estimated excess of $619(8.9 \%)$ deaths over the average for 1995 . About $62 \%$ of this excess may be attributable to increased air pollution. The excess mortality was slightly higher (768 deaths, $11.2 \%$ ) when compared with average daily mortality for 1993-94.

Excess mortality in Greater London was markedly higher than for England and Wales as a whole. This is probably because of higher temperatures (particularly the higher nighttime temperatures associated with the urban "heat island" effect" caused by the heatretaining properties of the densely built and paved urban environment, as indicated by the daily minimum temperature) and also because of higher levels of air pollutants. Figures from the 1991 census show that the population of London is slightly younger than that of England and Wales as a whole, however many other socioeconomic and demographic measures indicate that this population is relatively deprived. ${ }^{13}$ The proportion of the population from ethnic minority groups is much higher in London, which also has higher levels of unem- ployment, single parent families, dependants with lone carers, and reported long term illness. In addition, London has the highest level of households living in purpose built flats. A larger proportion of dwellings (almost a third) are rented from local authorities, and a smaller proportion are owner occupied than is the case nationally. The recent findings in inner city Chicago ${ }^{4}$ suggest that such deprivation increases vulnerability to heat related mortality.

These results accord with earlier findings that deaths from respiratory and cerebrovascular disease are affected most by both cold and very hot weather. ${ }^{3}$ Findings in the USA indicate that between one quarter and one half of the deaths associated with heatwaves occur a short time earlier than they would otherwise have done, as heat related peaks in daily mortality are typically followed by a temporary mortality deficit over the next few weeks. ${ }^{9}$ A study in Belgium found a deficit in daily deaths in the elderly after the excess mortality associated with a prolonged heatwave in $1994 .{ }^{14}$ No such analysis has yet been done in the UK, and-as is indicated in figure 1-any such forward displacement of mortality (sometimes called "harvesting") in relation to this particular heatwave would have been partly obscured by the hot episodes that occurred soon after it. Further insight into harvesting after the 1995 heatwave will only come from formal analysis of a much larger dataset.

Because the 1995 heatwave occurred relatively late in the summer it is probable that some seasonal acclimatisation had already occurred; furthermore, some of those most vulnerable to heat stress might have died in the earlier hot spells. This may explain why the peak in mortality is not as great as has been described for other heatwaves in England (for example, 1976). ${ }^{15}$

This study confirms that daily mortality does increase in very hot weather in England and Wales. Concomitant air pollution may have accounted for some of the excess mortality. These results are of public health relevance, particularly because they indicate that large urban populations may be more susceptible to heatwaves (and accompanying air pollution) than the rest of the population, both through relative deprivation and the "heat island" effect. This may well have implications for the need to improve housing stock, to provide better protection for the elderly, frail and bedridden, and to issue timely weather alerts when extreme events are expected. Increasing attention is now being paid to assessment of the health effects of global climate change, a process that is expected to cause more frequent heatwaves. ${ }^{3}$ This study provides quantitative information that is relevant to the prediction of such health effects.

The authors would like to thank colleagues at the UK Meteorological Office and AEA Technology for their help in providing data.

Funding: no external funding was sought or received for this study.

Conflicts of interest: none. 
1 Parker DE, Horton EB, Cullum PN, et al. Global and regional climate in 1995. Weather 1996;51:202-10.

Anon. Heat-related mortality-Chicago, July 1995. MMWR 1995;44:577-9.

3 McMichael AJ, Haines A, Slooff R, et al, eds. Climate change and human health. Geneva: World Health Organization, 1996.

4 Semenza JC, Rubin $\mathrm{CH}$, Falter $\mathrm{KH}$, et al. Heat-related deaths during the July 1995 heat wave in Chicago. $N$ Engl $\mathcal{F}$ Med 1996;335:84-90.

5 MacFarlane A. Daily mortality and environment in English conurbations. II Deaths during summer hot spells in Greater London. Environ Res 1978;15:332-41.

6 MacFarlane A, Waller RE. Short term increases in mortality during heatwaves Nature 1976;264:434-6.

7 McDowall M. Long term trends in seasonal mortality. Pop Trends 1981;34:16-19.

8 Kunst AE, Looman CWN, Mackenbach JP. Outdoor air temperature and mortality in the Netherlands: a time-series temperature and mortality in the Netherlan.
9 Kalkstein LS. Health and climate change: direct impacts in cities. Lancet 1993;342:1397-9.

0 Anderson HR, Ponce de Leon A, Bland MJ, et al. Air pollution and daily mortality in London: 1987-92. BMF 1996;312:665-9.

11 Parker DE, Legg TP, Folland CK. A new daily Central England Temperature series, 1772-1991. International fournal of Climatology 1992;12:317-42.

12 Bower JS, Stevenson KJ, Broughton GFJ, et al. Air pollution in the UK 1992/93. LR 1000. Stevenage: Warren Spring Laboratory, 1994.

13 Wallace M, Denham C. The ONS classification of local and health authorities of Great Britain. London: HMSO, 1996.

14 Sartor F, Snacken R, Demuth C, et al. Temperature, ambient ozone levels, and mortality during summer 1995, in Belgium. Environ Res 1995;70:105-13. 15 MacFarlane A, Haines A, Goubet S, et al. Air pollution, cliprosper and hong-term prospects. In: Charlton J, Murphy M, eds. Health of adult 